\title{
Perspectives on Gender Imbalance in Hotel Education: Reasons and Remedies
}

\author{
Dr. Mousa Masadeh \\ Dr. Mukhles Al-Ababneh \\ Dr. Samer Al-Sabi \\ Dr. Ma'moun Habiballah \\ Al-Hussein Bin Talal University \\ College of Archaeology, Tourism \& Hotel Management \\ Petra, Jordan.
}

\begin{abstract}
This paper investigates the gender imbalance in enrolment for university level hotel education in the Middle East. The research findings presented are drawn from interviews with Jordanian female workers in the tourism sector. This research aims to provide a better understanding of current labour conditions for women in the industry by identifying barriers to female entry into hotel education as well as offering meaningful insights into those barriers. This research involved monitored discussions with women based on focused questions about the hotel and tourism industry, education, religion and their local economies. As documented and analyzed in this paper, respondents offered a wide range of differing and conflicting opinions-from strong opposition to female participation in this type of workforce to full support of equal employment opportunities for women as a basic right. In many cases, participants dissented dramatically from the cultural and social expectations of their families and communities. In this context, the paper sheds light not only on the labour market within the local tourism industry, but also on the social and economic challenges as well as various social contradictions faced by Jordanian women.
\end{abstract}

Keywords: women, hotel education, tourism, hospitality, Jordan.

\section{Introduction}

The significance of the tourism industry is receiving increasing attention globally. Both developed and developing countries are highly interested in tourism for its benefits to the economy and overall national income. Tourism is among the fundamental pillars of the world economy, particularly in developing countries. In Jordan, it is one of the most important economic sectors, contributing to a growing and robust national economy. As a crucial industry, it plays a vital role in the development of the country's financial stability, with income from tourists representing a significant part of the national income.

Countries invest significant time and money into planning, marketing, and developing infrastructure for premium tourist sites that will attract higher-paying clientele and generate greater revenues. Accordingly, Jordan is exerting every effort, through a national strategy, to help increase the number of tourists and prolong their stay, as well as provide the best quality service in the hopes that they will return. Jordan also encourages Arab and foreign investors to visit, develop and augment hotel investments, resulting in more tourists and a greater influx of foreign currency.

Jordan is a small country in size and population, with a literacy rate among the highest in the world, at over $91 \%$. In spite of its small size, small economy and few natural resources, over the past few years, Jordan has experienced a substantial growth in the tourism sector and has achieved remarkable economic and social development. The growth in the tourist sector can be explained by a significant effort to improve tourist facilities. The Kingdom also encourages the growth and advancement of hospitality and tourism within the educational system. By offering relevant courses specific to this domain, Jordan shows prospective students that they are supported by their country. With twenty-six recognized universities, Jordan is also a great study destination for students from other Arab countries.

Hotel and tourism education is also considered an investment. Tourism in Jordan contributes $13 \%-14 \%$ annually to the gross domestic product (GDP), providing at least forty thousand jobs. However, the industry is still in urgent need of more trained and qualified employees to cope with current rates of development and growth. Therefore, a clear strategy is needed to train and qualify young people, both male and female, in order to contribute to sustainable economic growth. 
Despite the impression of gender balance in undergraduate enrolment for many fields of study in Jordanian universities, hotel management programs remain heavily male-dominated. According to the Jordanian Ministry of Higher Education and Scientific Research, the total number of female students enrolled in undergraduate programs for the 2017-2018 academic year was 115,453 out of 225,602 (Jordanian Ministry of Higher Education and Scientific Research, 2018). However, in hotel management, a significant gender gap is evident. Female students registered in Bachelor programs with a specialization in hotel management accounted for 90 out of $680(13.2 \%)$ students in 2011. The number of female students enrolled in the first year of Bachelor programs with a specialization in hotel management in Jordanian universities in the 2017-2018 academic year was 31 out of 171(18\%) students (Jordanian Ministry of Higher Education and Scientific Research, 2018). The disparity does not end there: by the time students complete their academic programs, these numbers usually have declined dramatically. This raises questions as to why there are so few women in this field, and whether social conditioning, lack of interest, a combination of the two or other factors are responsible.

\section{Literature review}

Gender roles vary widely around the world based on local social and cultural expectations. In Jordan, social, cultural and religious practices have enforced a sharp gender divide in many areas over the years.

\section{Women's participation in the tourism and hospitality industry}

The concept of women working and providing for their families is relatively new in many communities, especially in certain areas in the Middle East. In these areas, women's participation receives greater acceptance in some industries than others. Overall, female participation in the tourism sector seems to be viewed negatively and, as a result, many women have been encouraged to avoid working in this field.

Despite a wealth of research exploring gender and labour across various sectors, there have been very few studies to date exploring the role of women within the tourism and hospitality industry. There is little information on female hotel workers in the context of the Middle East, and virtually none regarding the situation in Jordan specifically (Masadeh, 2010, Masadeh,2013). Most likely, this reflects the low proportion of female workers in this sector in the country, which in turn seems to stem from entrenched traditional gender roles through which women are discouraged from participation in some fields (Würth, 2004).

As a result, women represent a negligible proportion of the labour force in Jordan's hotel industry (Magablih, 2000) and it is relatively rare to observe female workers in this male-dominated setting, in spite of their competence for the work. Indeed, researchers have pointed out the benefits of working to combat the out-dated attitudes that restrict women's full participation within and beyond this sector (Magablih, 2006).

This situation, of course, is not limited to Jordan. In the context of developed countries, it has been pointed out that female labour is "underutilized and undervalued" (Maxwell, 1997: 234). There is also plenty of evidence that women's participation in the hotel industry worldwide lags behind as a result of socio-cultural traditions (Baum, Amoah \& Spivack, 1997; Li \& Leung, 2001; Wong \& Chung, 2003). In Europe, the "old boy" network still holds sway (Linehan \& Scullion, 2001: 222), while occupational roles are split along "masculine" and "feminine" gender lines in societies like Japan, Germany and the U.S. (Treven, 2003). On the other hand, despite being limited to lower-ranking positions, women do seem to make up an increasingly significant and growing proportion of hotel employees worldwide (Baines, 1998; Lee \& Chon, 2000). Ultimately, women's participation in this sector depends greatly on the cultural norms in place within a given region. As the current literature indicates, it seems likely that the impact of globalization, the international tourism economy and the spread of international hotel chains will positively impact women's opportunities, ultimately improving and normalizing their full participation within the industry itself (GröschI \& Doherty, 1999).

\section{Women in management roles in the tourist and hotel industry}

Despite women's growing participation in the workforce worldwide, they are still relegated to lower paying and lower skilled work, and are relatively absent from upper management positions compared to their male counterparts (Biswas \& Cassell, 1996; Davies, Taylor \& Savery, 2001, UNWTO and UN Women, 2011).

According to Kattara (2005), in Egypt, which is, in many respects, typical of Arab countries, women constituted a mere 13.2 percent of hotel managers, and only three women in the entire county occupied upper management positions. Likewise, Lie and Leunch (2001) found that, in 77 hotels in Singapore, only two general managers were female, and according to Pine (1997), only three females were general managers across 72 Hong Kong hotels. In Jordan, meanwhile, only 33 percent of middle managers are female (Masadeh, 2010). 
An Australian study found 34.5 percent of managers were female in multinational chain hotels (Timo and Davidson, 2005), The highest female representation in hotel management was reported by a study in the U.S.; 46 percent of chain hotel managers were female, although they tended to be limited to certain areas (Woods and Viehland, 2000).

The global situation in terms of gender, labour and the hospitality industry tells a similar story: women comprise only 4 percent of middle or senior management and 1 percent of upper management (Jones, 1992). In 1999, a study of 76 countries found that women's employment in the tourism industry-including catering, restaurant and hotel employees - was relatively higher compared to other sectors, accounting for approximately 46 percent of workers on average. Depending on the region, the percentage ranged from 2 percent to over 80 percent female workforces, but generally split fairly evenly in half between men and women in places with longstanding tourism economies. Still, the study confirmed that low-paying, part-time and seasonal positions were skewed disproportionately toward female workers.

\section{Cultural factors}

According to Lie and Leung (2001), the social and cultural barriers that restrict women's promotion opportunities operate largely independently of particular organizational practice and procedure.

In this light, it becomes increasingly important to understand the tensions between traditional customs and the modern impetus toward equal employment opportunities, as well as the ethical implications for female employees on a local scale. For instance, in Jordan, women are generally forbidden from sleeping outside of their homes. Women's attire also differs from men's - it is not mandatory to wear a veil, but women are usually dressed formally and modestly. Perhaps most importantly, when it comes to "socializing" with the opposite sex, women may face harassment or discrimination on this basis. These are just a few indicative examples of why many locals remain uncomfortable with women working in hotels and the tourism industry, as this type of work would require them to depart from each of these norms. Also, of course, such work could be seen as interfering with women's traditional duties as wives and mothers.

A study in Egypt revealed four key factors that limited women's opportunities for promotion to higher positions. First, in contrast to men, it was felt that marriage would interfere with their job performance. Second, it was believed that women would not be equally mobile in the case of transfer to a different location, which often accompanies higher positions. Third, women would have to work harder to accomplish the same level of effectiveness. And fourth, social and cultural restrictions held women back from career advancement (Kattara, 2005). In Jordan, marriage is viewed as a sanctified commitment that must not be broken, and which could potentially be tainted by outside employment competing with traditional duties. In these cases, modern Jordanian women are faced with the decision of how traditional of a life they want to lead.

A landmark regional study of these issues, considering the dearth of research on women and labor in the Middle East, reinforced the idea that a female general manager is virtually unheard of and even unimaginable in the male-dominated world of business (Kattara, 2005: 246). This reflects the traditional Arab view of women and family life. Other traditional cultures may reproduce similar restrictions. In China, for instance, as Wong and Chung report, the traditions of Confucianism have similarly enforced patriarchal forms of social organization that subordinate women to men (Wong \& Chung, 2003: 72). Nevertheless, progress and economic reality would seem to dictate that, as these views gradually continue to evolve, women will be increasingly recruited into the workforce.

In Jordan, one factor restricting equal opportunity employment is the widespread practice of nepotism (Hayajenh, Maghrabi \& Al-Dabbagh, 1994: 66). Nevertheless, women do participate regularly in other industries demanding latenight shift work, such as the health sector.

\section{Economic aspects of employment in the tourism and hotel sector}

Meanwhile, the impact of the tourism industry on any growing community and economy cannot be denied. Indeed, it is a sector that affects the lives (and livelihoods) of everyone, whether directly or indirectly. The World Travel and Tourism Council reports that institutional support from governments is crucial to sustaining development of a country's tourism sector, particularly in developing countries (World Travel \& Tourism Council, 2011).Travel and tourism accounts for some 260 million jobs around the globe, which spur the growth and health of entire communities. Interestingly, women's increasing participation in the global tourism sector has proven profitable, suggesting economic potential for countries that seek to embrace female labour in the industry. Nevertheless, women earn up to 15 percent less than male workers in equivalent positions (Abu Ghazaleh, 2011). 
In Jordan, women account for 48.6 percent of the workforce out of a population of six million (The World Bank, 2012). Needless to say, female workers can potentially contribute enormously not only to the workforce, but the tourism industry and the economy in general.

Elsewhere, women's participation in the tourism industry is not so fraught. In Canada, where tourism accounts for some two percent of the country are GDP, the industry employs over half a million people, representing 3.5 percent of employment nationally. The impact of the Canadian tourism industry on the economy is on a par with the combined economic impact of the fisheries, forestry and agriculture sectors put together (Statistics Canada, 2011). Interestingly, according to Pierce (2011), in Canada and the United States, this industry tends to include a higher percentage of female or visible minority business owners compared to other sectors. This speaks to a relatively greater acceptance of female participation in the industry compared to a country such as Jordan.

\section{Supporting education for women}

Jordan's Minister of Tourism and Antiquities, has suggested women be included in greater numbers in the industry through post-secondary programs, clear benchmarks for career advancement, and media campaigns to raise awareness and normalize the image of female tourism workers (Abu Ghazaleh, 2011). In this context, awareness and education are identified as the keys to social change. Moreover, it would be necessary to emphasize that women's traditional values need not be compromised to participate in the sector.

An example of public education and outreach can be found in the World Tourism Organization, which has made efforts globally to illustrate that women should not be restricted to any career or lifestyle, and that they are qualified and deserving of just as many opportunities as men. The Organization holds seminars around the world emphasizing the opportunities women may be missing in the tourism industry.

\section{Women's strengths in the hotel and tourist industry}

Moreover, it has been argued that women's management styles tend to include positive qualities that make them well suited to positions of organizational authority. For instance, women are often associated with qualities like strong communication, teamwork, sensitivity, transparent standards and adaptability compared to male managers (e.g. Smith \& Smits, 1994; Shirley, 1995, both cited in Maxwell, 1997). In terms of the hotel industry, while male managers tend to prioritize financial milestones, female managers seem to place a greater emphasis on customer satisfaction (Peacock, 1995) - a perspective that can help ensure greater long-term profitability and organizational success.

In the hotel and tourism sector, the qualities associated with female employees have made them especially beneficial. However, in 4- and 5-star international hotel chains, although most front line positions tend to be divided relatively evenly between men and women, management remains male-dominated (Wong \& Chung, 2003; Timo\& Davidson, 2005).

According to the Tourism Global Value Chain, Jordan "is growing as an international tourist destination. Tourism is the largest export sector... [and most] of Jordan's tourism is focused on cultural and religious tourism, centered around Petra, a historical and archeological city constructed of rock in the $6^{\text {th }}$ Century C.E." (Christian et al., 2011: 30). The focus on culture and religion in the tourism sector offers all the more reason for women to embrace these traditions within the industry, teaching tourists about customs like wearing veils, local cuisine and spiritual beliefs. Tourists are increasingly drawn to "authentic" local experience as opposed to the standard corporate treatment they would receiveat any other big chain hotel (e.g. Hilton Hotel in the United States).

\section{Methodology}

The present study employed a qualitative approach, namely focus groups, to explore attitudes toward the dearth of female students pursuing education in the hotel industry. Following Prince and Davies (2001), small groups (comprising of six participants) were used to allow sufficient and varied discussion under specific time constraints. For the purpose of this study, four separate focus group sessions were held in four separate universities in Jordan, with each group composed of six female university students. The focus groups wereheld in Arabic.

With participants' signed consent, all sessions were recorded on tape and transcribed. In the interest of confidentiality, all informants remained anonymous and were given access to results.

After the interviews were conducted and transcribed, direct and inverse translations (i.e., into native and non-native languages) were carried out by two accredited translators. To ensure accuracy, the English translations were subsequently translated into Arabic by two additional translators with no access to the originals. No major discrepancies were observed between the two sets of translations. 
Participants' responses were then analysed using qualitative content analysis (Krippendorf, 1980; Weber, 1990). On the basis of their recurrence in the responses, the most salient quotations along with major themes were identified (Krueger and Casey, 2014, Carey and Asbury2016). Direct quotations are included below in order to animate and substantiate the findings with the authentic voices and experiences of participants.

\section{Findings}

During the interview sessions, a number of thoughts and opinions were collected from the subjects, helping to establish what a variety of people in Jordan think regarding women working in the hotel industry. On average, each focus group produced 5,843 words spoken, falling within the typical range noted by Schmidt (2001) of 5,000-8,000 words.Qualitative analysis of the focus group results revealed a number of recurring themes, which have been grouped according to the subheadings below.

\section{Social factors:}

\section{Family Life, Expectations and Obligations}

The concept of women staying home to care for their families is still prevalent around the world in some form or another. Some cultures uphold this value through rigid traditional gender roles, others dissent strongly from such an idea and others remain somewhere in between. In all cases, women may feel that they must abide by their society's expectations; otherwise they may risk social judgment for re-entering the workforce or joining the workforce at all. One subject said that "working women usually feel blameworthy for not being able to be there for the kids all the time. Similarly, non-working women can experience the same feelings." It was also said that children, "especially in the first year, need both their parents and more notably, the mother."

Historically, biological mothers have been the primary caregivers for infants. They are not only the source of sustenance for the child in the early time of their lives, but they also form a stronger bond with the child they bore for nine months. While a father or nanny might stay home to care for the child, the bond is not the same as the one between mother and child. It may be for this reason that one subject said that a parent's "absence may have a profound physical and moral effect on children. Nannies do not replace mothers, they solely complement them." Another person shared that the "role of being a mother is a demanding one. It requires a lot of patience, tenderness and warmth for which nannies cannot make up."The bond created between a mother and child is one that cannot be duplicated, according to many.

Family roles can vary from country to country and between regions, with social, cultural, religious and financial differences all affecting individuals' points of view. One participant said that fathers are the ones who tend to "preside over their families in love and righteousness and are responsible to provide the necessities of life and protection for their families. Mothers are primarily responsible for the nurturing of their children."Although it is true that in nature, females are generally the nurturers, this does not mean that this is their primary function in life. After all, many women do not have children of their own. Women should be considered equal members in other spheres of society, regardless of their potential role as a mother or wife. It is likely for this reason why the following participant shared this thought: "Women are encouraged to lead full lives; balancing career, children and marriage in order to be perceived as successful. Some feel this is bad for children who are then cared for by a babysitter/nanny, nursery, or a member of their extended family. Others feel that no harm comes to children if the alternative care is good and that children may in fact benefit if paid work makes the mother happier and her work improves the family's living standards. Occasionally, fathers will also decide to stay home to care for the children and household instead of the mothers. Many studies point to the years before a child starts school as the most important in its mental and emotional development. For this reason, it could be perceived that it is crucial for women to be home during these years with her children. The counter argument is that children will develop just as well, or even better, with support from others in addition to their mothers. In the context of this debate, I use the term 'housemother' to express a mother who stays at home to look after her children, and 'housefather' to mean the same thing in relation to their father."

The above participant is saying that women should be allowed to make a choice. There is no right or wrong answer, so long as their choice is what is best for the family. In many situations, the mother will be happiest returning to the workforce after having children. In these situations, the children are likely better off with a happy part-time mother as opposed to a miserable full-time mother; their time together will be much more precious.

Family expectations are also a large part of Jordanian culture, as one participant indicated by saying; "Working is not a vice, provided it is convenient for women; my family would never allow me to work in a hotel." One young woman noted that she has a friend who graduated from university with a specialization in hotel management, and she couldn't work in a hotel as her husband refused to let her work in this field. Nevertheless, she found good work and well paid 
positions elsewhere. Another participant painted a sad picture regarding the prospects for family life,noting that "some Jordanian families would not allow women to work in hotels as they are fully cognizant of the environment. I have witnessed a lot of girls that are working in hotels or restaurants and they are either still not married despite being over 30 years old or they are divorced."

Demonstrating the clash between local and Western cultures, one participant exclaimed: "My family would never allow me to work in a hotel; do you think you are in the U.S.A.? Give it a second thought and redeem yourself. Otherwise, you won't be happy with the outcome!" This is representative of an attitude that is, it may be argued, ultimately harmful to Jordanian society. Another participant stated that "Jordanian girls face some kind of opposition from their parents despite the fact that Jordanian society is on the route to emancipation... Girls are naturally shy; they have been brought up in a conservative society. Eventually, she will accept facts and reality." These girls struggle to educate themselves and assert their identities as working women because they are facing such opposition from their families.

Families want to maintain their dignity and family honor. One participant said that "as far as working in hotels or swimming pools or night clubs, a female from Jordanian tribes or Bedouins would not allow their honour to vanish in thin air!" They believe that by allowing women to work in the tourism industry they and their families are being dishonored.

Women are often seen primarily as mothers and wives, and one participant represents a common view when she argues that a woman's "job must not be detrimental to her family duties; she has children and a husband to look after."

However, some believe that the lack of employment in the area can drive them to positions in the hotel industry. One person shared that "Jordanian women started to undertake jobs in hotels due to lack of other jobs in other sectors, such as public relations, reception or marketing." Their families will have to come to terms with the fact that they are simply pursuing the jobs that are available to them, not dishonoring their families.

One participant shared that she disagrees "with women pursuing... hotel education. We do not have the same rights as men. A woman should be under the aegis of her parents till she gets married, and her husband can then take control. She must take care of her family and raise kids, preparing them for the future. We should not accept children being raised by servants and chauffeurs because their mothers are too busy to look after them. It is incumbent upon women to fulfill their duties towards their families and pay heed to their reputation." This view of women in the workplace affects the entire country and economy. Stating that women and men do not have the same rights is only furthering the gap between the genders.

Ithas even been proposed that working women "deteriorate half the society... they get maids or nannies to help her during her absence?" This should be an afterthought if women want to join the workforce. Another one opposed by saying "No person in the workforce is "deteriorating" society, they are contributing" and also added "women and men should be considered equals both within and beyond the workplace."

\section{Shift Work}

As illustrated in the literature above, women are often identified as the "weaker sex," in need of protection. On this basis, many participants balked at the notion of women working night shifts. One participant opined that "night shifts scar women's reputations; it is against [Jordanian] traditions and culture, women should be exempted from night shifts and men should readily commit themselves to doing night shifts.'If women are not permitted to work night shifts, however, they cannot be considered as equals in the workforce. The following participant comments on the fact that certain industries simply require all workers to work at different times of the day: "Certain jobs demand that women do night shifts, such as in the hotel industry and nursing." While another participant said that these "jobs must be carefully scrutinized to hinder further problems."Presumably, these "problems" involve the role of gender in the industry and the fact that members of the society have had complaints about women working night shifts in hotels.

One said that women "doing night shifts might be harangued and could be subject to harassment. However, the job remains a very important part of women's independence, helping her achieve her personal goals and better her selfesteem and therefore, contributing to improving the place of women in the labor market, in society and in decisionmaking positions in the Arab world." This person comments on a valid point, that while women may be scrutinized for working night shifts, it is crucial for them to take a step forward and, if they want to work in a hotel, they should pursue it."In the tourism and hotel industries, employees such as stewardesses, receptionists and tour guides may all need to work night shifts."One participant said that "patience and seriousness are the keys to surmounting all impediments in spite of our deeply rooted traditions, culture and religion and in spite of the entire job's negativism."

\section{Mixing}


Cultural laws are strict in the minds of many in Jordan. One participant in the interviews expressed that mixing "between men and women is forbidden. Do certain rules and conditions need to be stipulated to allow men and women together in the same place as in hotels?" This kind of traditional thinking would ultimately disqualify women from many jobs in the regular workforce.

Another participant asked if they could "compel women in need to leave their job." This type of negative connotation illustrates a widespread lack of knowledge and respect for women in the workforce. Such a frame of mind is likely caused by the scarcity of women in the workforce, whereby men are accustomed to interacting with women in the personal, rather than professional, sphere.

One participant asked: "What is the difference between hospitals and hotels where everybody works in front of people? Nowadays, women can sometimes wander with men." This interviewee demonstrates a more modern thought process, implying that there is no issue with men and women interacting in the workforce. "The problem lies in [their] culture," She added. "Working alongside men in hotels, hospitals and airports is not problematic." Men and women should be able to differentiate between their personal and professional lives in Arab countries, like they do in many other countries worldwide.

Finally, another participant said: "Is it more inconvenient for women to work in markets than bring in expatriates? Our country eventually suffers the consequences. Do women work for fun? Women should work to meet our society's needs. There are two types of women: needy women and those whose aim is to bring their expertise into our country's service: her work is associated to benefiting the society." This is indicative of the constructive idea that all members of society are capable of contributing to the country's economic development.

One participant said that she agreed that "women in Jordan are worthy of the positions they occupy; there is the minister, the senator and the manager. Law does not recruit a man or a woman. There has been disparity through the ages; men were given a better chance of getting hired than women because they are meant to provide for their families. However, recently, the competition takes place between the two sexes." This woman is suggesting that roles be shared and that rules ensuring equal opportunity are enforced. However, not all women feel this way. Another participant shared that she supports "women working in hotels, however, her duties are to be limited to the office where she is isolated from men." This illustrates that women in Jordan have not reached a consensus regarding their role in the workforce as of yet. Also, many women may feel that they cannot associate with men in the workplace, which limits their employment opportunities.

\section{Education}

Education is key to encouraging any member of society to participate and contribute to their utmost potential. Unfortunately, not all communities encourage their members in this regard. One person surveyed said that education "and changing the curricula, cultural illumination and an insightful comprehension of religion amply contribute to improving our society's views and broadening its horizon. The media is one of the most powerful influencers of improving women's role and it has the ability to alert the general public about the importance of the female labor force. In spite of the oppressive structural and legal barriers, women have shown remarkable resilience and have been able to preserve their place in an industry which is well suited to their skills."

This being said, the next generations should be taught acceptance and why it is important to have both genders participate in the workforce. Even women educated in hotel management are not sure of their roles. One woman said that she has her "diploma in hotel management and would never work in such places no matter what." Another participant shared that nobody "is forced to work in a sector where he or she does not feel like working." Finally, another shared that she supports "working in hotels, but I don't support studying hotel management because if any girl goes to a hotel, if she is beautiful, she will be hired on the spot; I mean that hotels want girls because of their look and some men go to hotels where the women working are attractive... so why do I waste 4 years of my life if I can find work in a hotel right now?" The above comments illustrate that even if women are educated in hotel management, there is still confusion as to whether or not this is acceptable in their communities. One participant shared that female "education in tourism has a positive impact on [their] society and helps augment the national economy and development of human resource management." This participant is thinking in a progressive way that supports women's role in helping Jordan's growing economy.

\section{Location}

Where an employee works can have a great impact on many aspects of their life, from commute times and transportation costs to time spent with family and so on. In extreme cases, women may be subject to unacceptable bullying as a result of the physical location of their work. As one participant shared, women who work "in remote 
hotels are subject to gossip and negative innuendo: there would be nobody to help her should she get in trouble. Incurring the high commuting expenses is deemed unsatisfactory." This mindset is associated with the retrograde notion that women are frail and require defending.

\section{Religious factors}

One participant said that women "are allowed to work in Islam. However, it does stipulate that some restrictions be followed to safeguard the dignity and honor of women and the purity and stability of the Islamic society; the conduct of women, after all, is the "backbone" of any society." This representation of women makes it difficult for them to progress in the workforce as they face extreme religious pressure to conduct themselves "perfectly."

Because Islam is so pertinent in the lives of many Jordanians, they consider its word to be fact and will not disobey their beliefs. For this reason, one participant shared that a "job is not permissible; women are not allowed to work in bars, restaurants or night clubs in hotels. The job must not take place in a repulsive environment and she should not be operating amongst foreigners, which happens to be contradictory to Islamic culture."Regarding women pursuing hotel management studies, another participant shared that they "do not support that at all; it does not come in accordance with Islamic rules where women have contact with women, and there is also the presence of alcohol in these places."

One student stated: "Women in the hotel industry represent a sensitive topic as far as the Jordanian community is concerned. People think that letting women work in the hotel industry will jeopardize tradition and customs and religious values."Generally speaking, most highly religious followers do not support women working in the hotel and tourism industry.

\section{The veil}

Religiously, many women in Jordan are required to be veiled. Removing this veil or choosing to not wear one at all is a personal choice that women have the right to make. One interviewee shared that women are "segregated in the hotel industry. Therefore, they have been giving up on the veil in order to facilitate being employed. Long hair, make up and non-conservative clothes are quite common in the hotel industry."One woman also shared that she is "fully veiled so it won't work out for [her] to work in a hotel." She would not consider changing her way of life or her beliefs to work in a hotel. Others feel that it is important to wear their veil in order to not be discriminated against. One woman reported that, in order "that women shall not be harassed; some women are conservatively veiled when working in hotels. Some hotels need female employees, as women know how to deal with a female who understands their needs." Another participant advised that "all veiled women not study hotel management since once she graduates; she is faced with the reality that veils and work in hotels do not go together."While many hotels may allow women to be veiled during working hours, others may enforce strict dress codes that preclude veiling. However, veiled women face challenges in the tourism industry not only from other people, but also from their own beliefs and customs.

\section{Alcohol}

Images of alcohol have become a standard reference point in popular culture, used around the world as a sign of partying and socializing. Many religions, however, take a strong stance on forbidding or limiting alcohol consumption. One participant shared that "Islam takes an uncompromising stand towards alcohol and forbids its consumption in either small or large quantities. Islam not only prohibits drinking alcoholic drinks, but also prohibits making them. Islam also prohibits carrying, selling, or buying such drinks."

While another participant shared that "it is illegal (haram) to work in hotels where alcohol is served even if the job happens to be administrative and has nothing to do with serving alcohol. Apparently, working in these hotels requires the serving of alcohol. Me, as a student in the university, I would undertake any of the positions in a hotel except those that involve alcohol or work that involves inappropriate behaviour; I often criticize people that I presume are ignorant for still adhering to old and outdated traditions. To them, girls working in hotels will be exposed to unacceptable circumstances and thus might have their reputation marred."

To demonstrate the extent to which alcohol in the workplace can affect a women's life, one participant expressed that "[his] sister was offered a job as an accountant in a hotel serving alcohol. She desperately needed an income as she was divorced and needed to provide for her children."

One woman shared that her "fiancé is an accountant at a hotel where alcohol is served, which has been taking place for over 5 years. We completely rely on his income to provide food and pay for our housing. We have one child." She supports him despite the fact that alcohol is served at his place of employment. It must be considered that tourists will likely want alcohol while visiting and on holidays or business trips, since not all religions forbid alcohol. Thus, if the Jordanian economy wants to continue to grow, these establishments will continue to require staff. 
One girl insisted that "working in hotels where alcohol is served and is forbidden by their religion, it is a sin. The income is, religiously speaking, haram [religiously illegal]. You have to redeem yourselves and good riddance to the money is what I say." Unfortunately, not all women can ignore the financial incentives of such jobs. Even if other, lower-paying jobs are available, this may not be an option for some women based on their financial situation.

\section{Competitive Rates of Pay}

Historically, the wages of men and women have differed from industry to industry. One participant shared that "companies and institutions always crave profit. Women's average income is much less than men's income, and this large earning gap gives hiring preference to women." It is true that companies always seek to maximize profitsin order to thrive. If women are paid less than men, it may be in the company's best interest to hire women at less competitive rates. This point was advanced by another participant, who said that in the current cultural climate, "profits have enormously increased because products prices have decreased as a result of hiring women. Capitalism seeks profits and women are the least of their worries." If a company is able to get ahead by hiring women, then there is no good reason not to, assuming they are ready and willing to work in hotels. On this note, the question should be raised as to why women are not valued as much as men in the industry. If men and women are equally educated and qualified, then their rates of pay should be comparable as well.

\section{Economic and other societal considerations}

Jordan has a growing economy that will benefit from a growing tourism industry. The country's economic woes incite people to search for jobs, even some kinds of hotel work that are religiously illegal (haram). While some consider such jobs sinful, others regard them as normal. One participant said that women "have proved their capacity to work under stress and proved themselves as employees in many domains: hospitals, banks, administration, customer service, secretariat. Jordanian women have initiated many jobs in engineering, and are equipped with lots of enthusiasm and zeal to serve the country, its people and its tourists."In this participant's eyes, women are ready to contribute to Jordan's growing economy. Also, from a political perspective, one participant shared that "it is a right to work in such places" and that "society will change its attitude about women working in the hotel industry because of the financial need."

One participant said that "as long as she possesses the competencies and the capacities, she can work wherever she wants to. She enjoys working in places where she can make new acquaintances."

Another participant said they are "supportive of women working in hotels which for [them] are quasi hotels with administrative, accountancy, coordinative, marketing, organizational departments where there is no direct contact with men." Similarly, one shared that working "in hotels does not mar women's dignity, with the provision that she remains professional and loyal." Women and men are both fully capable of contributing to the workforce while remaining professional and dignified. Unfortunately, there are still dissenting views from some communities, as demonstrated by a participant who reported that, in their "village, as far as women and culture are concerned, it is deemed inappropriate for a woman to seek employment in hotels."

One participant, when asked if she agreed with women working in hotels, responded: "of course, I do. Women constitute half the society and however should work in accordance with good manners." This is the kind of thinking that will allow Jordanian society to progress and the economy to grow by enlisting the community as a whole to their full advantage.

\section{Resources}

Average resources and income in Jordan, according to one participant, are "relatively low and families survive by combining the income of both parents. Women have, therefore, started applying for jobs in hotels." This is a combination of choice as well as necessity. Also, according to one person, women "are relatively reluctant to work in tourism due to inadequate and poor resources and lack of training...culture and tradition are also a hindrance when it comes to women and tourism, particularly in hotels... in our society, women are subject to different misconceptions impeding development and progression." Many interviews demonstrate that jobs for women are permitted but are still in need of constituents. Yet, women do not have the possibility to work flexible hours. If all members of the Jordanian society were treated, trained and employed as equals, then the economy would thrive. Sadly, attitudes like those expressed by some participants make it difficult to take women in the workforce seriously. "Due to the lack of resources in Jordan, there is undoubtedly a need for women in the hotel and tourism industry." They shared that fifteen years ago, Jordanian women were not allowed by their families to work alongside men in the tourism sector or banks. Unemployment is rising with the increased population density, high prices, diminution of public jobs, and lack of diversity of university specialties. So "we are not to prevent women from working in many domains. Why could women not contribute to the prosperity of our country by working in tourism and hospitality industry, including hotels 
and restaurants? By not allowing this, we are hindering the prosperity of the country. Women work at reception in hospitals, health clinics, private clinics, private companies and laboratories alongside men. We are faced with the problem that we do not want women contributing to the prosperity of our society. It is not a time for squabbling, our current conditions require courageousness and women need trust to be able to function."

\section{Psychological factors}

Working is not only about income. Men and women work in order to feel fulfilled in their lives as well. One person shared that having "a job is extremely important, as it allows your creativity to flourish, helps you feel useful, make ends meet and interact properly with others." People want to work in order to grow as individuals as well as to make a living. Another person shared that when "you go to work, you are helping out society." By helping your community, you will likely feel that you are making a worthwhile contribution. Men and women should both have this opportunity, but, as one said, there is "no turning away from the fact that female independence is harder to earn than that of a male, and therefore, more treasured. Independence means so many different things to so many people - to someone it may mean having a roof over your head that you can call your own; to another it may mean getting out of a dysfunctional relationship."

\section{The Female Image}

This section is focused not only on the way women are represented, but also on the way women are compared to men. Some female students interviewed noted the importance of women's roles and of their being allowed to work in all domains in both the private and public sectors. There are women working in governmental sectors, and they regularly deal with and serve men. Many women now work in the tourism sector, which presents many job opportunities for women. People have begun to understand and accept that competent and experienced women have the right to participate in improving the development of our beloved country.

Another student noted that, biblically speaking, "men and women were created to complete each other. Each has his or her own role which may differ or be alike; men have been endowed with some physical qualities enabling them to perform certain duties. Women, likewise, should be able to function accordingly."

On a similar note, one woman exclaimed that "women should be allowed to do all kinds of jobs. End unfairness! The world is hastily developing and mankind has reached the moon. Give women their freedom!" Another insisted that they "strengthen the role of women working in our society and preserve their roles as mothers and a housewives. She can accordingly provide for her family."

Unfortunately, despite the desire for complete freedom from society's binds, "women are still subject to pending decisions which impede their chances of finding jobs, and society rejects her complete rights. Women in Jordan working as receptionists are very good at their jobs."

One noted that, "stereotypical attitudes towards women, not allowing them to make decisions, show how hypocritical our society is." One said that she doesn't see the difference between a woman working in a hotel and a flight attendant; she said "I had a dream of fulfilling my wishes to become a flight attendant; I realize it would be in vain to fantasize, as my family wouldn't accept my choice and my finances are very conservative, so I stopped dreaming." Women should not feel that education in a certain domain is nothing but a dream. They should be excited and encouraged to further their education.

\section{Discussion}

Only 16 out 24 women interviewees seem to support women working in the hotel industry. This illustrates that men are not the only ones unconvinced that women should be working in the hotel industry. In order for women to advance, be educated and work in the hotel and tourism industry, they themselves must also be convinced that they are capable of taking on the challenge.

Views regarding women working in Jordan's hotel industry are sharply divided between those who strongly agree with the practice and those who strongly oppose it. The main themes that seem to contribute to the debate around women's participation in this field focus on family life expectations for women, the role of education for being hired in this field, cultural and religious influences (i.e. women working late at night due to shift work, mixing with men in the workplace, working in non-urban areas and the overall image for females). More specific religious considerations were emphasized such as the role of Islam in allowing women to work, the role of the veil in this work area and the role of alcohol which is usually part of this service industry. In addition to these sociocultural and religious factors, participants also discussed more practical considerations, including economic needs and the right of women to employment and pay considerations. These findings confirm, for the most part, existing literature describing contributors to the low 
participation of women in this field (Würth, 2004; Kattara, 2005; Abu Ghazaleh, 2011). The importance of employment for the psychological well-being of women was also discussed among participants. Those who disagree primarily feel that it is contrary to Islamic and Jordanian culture. There is a prevalent mindset that women's primary social roles are those of mothers and wives who should not leave their families.

Such attitudes are keeping many women out of the workforce, to the detriment not only of individual women and families, but of the economy of Jordan. Those who support women working in the hotel and tourist industry express that women are just as capable as men of performing meaningful work in their communities - in addition to being wives and mothers. Tourism is on the rise all over the world, and in order to take advantage of the financial benefits, Jordan will have to use all resources at its disposal, including the fully capable and qualified female workforce.

In 2004, the tourism sector employed 21,430 male employees and 4,391 female employees. Since then, due to the growth of this industry, the sector has experienced a significant rise in employees of both sexes, with 41,879 male employees and 4,391 female employees in 2011. In 2016, the number of male employees in hotels specifically in Jordan reached 19,139, while the number of female employees was only 1,553 . These numbers indicate that the despite the overall growth in numbers, the increase in ratio of female to male workers, as well as the increase of female workers in general, has therefore been negligible (Tourism Statistical Newsletter of 2016:the Jordanian Ministry of Tourism and Antiquities).

Although we are living in the 21st century and the tourist sector is clearly in need of labor, women are still facing stigma for their interest in the industry, which typically stems from customs and traditions in terms of requiring night shifts, long working hours, dress codes and socializing with men. The majority of women are not keen on working in this sector, since more work is needed to gain acceptance for this line of work in their communities. Many women want to have a deeper purpose in life, and those who are not married and do not have children may want a career. Those who are married with children may also feel that they need a bigger challenge, and want to join or rejoin the workforce.

Women should not feel segregated because of their gender. They can be qualified and educated members of society and of the working class. Other than traditional religious and cultural values, there are few compelling distinctions between men and women in terms of suitability for working in the hotel and tourism industry. In cases such as these, women need to choose the lifestyle they want. If they choose traditional religious and cultural lives, they are unlikely to be educated in the hotel and tourism industry.

In Jordan, there have been concerted and ongoing efforts to achieve women's empowerment and gender equality across various domains of public and private life. This includes efforts to increase women's and girls' economic rights and opportunities, promote women's entrepreneurship and reduce gender separation in order to empower women as decision-makers. However, despite tremendous progress made toward women's empowerment, significant challenges still face women throughout their lives. The lack of understanding in their communities restricts their personal and professional development. Changes will have to take place on a large scale in Jordan before men and women are considered equals.

The great Mahatma K. Gandhi once said:

To call women the weaker sex is a libel; it is man's injustice to woman...There is no occasion for women to consider themselves subordinate or inferior to men...A woman's intuition has often proved truer than man's arrogant assumption of superior knowledge... Woman is the companion of man, gifted with equal mental capacities...If nonviolence is the law of our being, the future is with woman. (Quotations compiled by Tikekar, 2007).

If this notion of equal mental capacity were enforced, women could be encouraged to work wherever their skills were of the most use. Most brilliantly of all, Gandhi stresses that by putting women down, men are hurting themselves most of all. As he so elegantly asserts, men and women are equals, and neither would survive without the other.

Jordan would benefit both economically and socially from encouraging women's employment and education in the hotel industry while, at the same time, emphasizing public education to raise public awareness as to the advantages of women contributing to the workforce. After all, women presently constitute an essentially untapped resource in Jordan, and the time is ripe to address the situation. 


\section{Conclusion}

The focus groups that contributed to this research, offered valuable insights into the current context around women's role in the workforce, common societal and cultural perceptions and barriers preventing women from entering hotel education at the university level in Jordan. The female respondents offered a wide range of differing and conflicting opinions - from strong opposition to female participation in this type of workforce to full support of equal employment opportunities for women as a basic right.

In many cases, participants dissented dramatically from the cultural and social expectations of their families and communities. In this context, the paper also sheds light on the labour market within the local tourism industry and the social and economic challenges faced by Jordanian women.

As Jordan has become one of the pioneers in tourist services on both a local and global scale, creating a demand for more resources in this sector, women's participation could greatly benefit the expansion and enhancement of this industry. This would also be consistent with the country's concerted and ongoing effort to empower women and promote gender equality across various domains of public as well as private life. This paper provides information on a range of aspects that could be considered to facilitate the inclusion of women in hotel education at a university level and ultimately their participation in the tourist service sector.

\section{References}

Baines, A. (1998). Technology and tourism. Work Study, 47(5), 160-163

Baum, T., Amoah, V., \& Spivack, S. (1997)."Policy dimensions of human resource management in the tourism and hospitality industries."International Journal of Contemporary Hospitality Management, 9(5/6), 221-229

Biswas, R., \& Cassell, C. (1996). "Strategic HRM and the gendered division of labour in the hotel industry: A case study."Personnel Review, 25(2), 19-34

Canadian Tourism Commission. (2009), Driving tourism business through difficult times: Annual Report, 2009a. [online] available from<http://en-corporate.canada.travel/content/ctc_news/2009_annual_report>[01 October 2016]

Carey, M.A. and Asbury, J.E., (2016). Focus group research.Routledge.

Christian, M., Fernandez-Stark, K., Ahmed, G., \&Gereffi, G. (2011)."The tourism global value chain: economic upgrading and workforce development. Skills for Upgrading, 276

Davies, D., Taylor, R., \&Savery, L. (2001). "The role of appraisal, remuneration and training in improving staff relations in the Western Australian accommodation industry: a comparative study."Journal of European Industrial Training, 25(7), 366-373

Abu Ghazaleh, H. (2011). From Vision to Reality: Politics and Gender in Jordan's

Tourism Sector[online] available from http://www.wilsoncenter.org/sites/default/files/9-23\%20Abu-Ghazaleh\%20PowerPoint.pdf[11 November 2016]

Gröschl, S., \& Doherty, L. (1999). "Diversity management in practice." International Journal of Contemporary Hospitality Management, 11 (6), 262-268

Hayajenh, A. F., Maghrabi, A. S., \& Al-Dabbagh, T. H. (1994). "Research note: Assessing the effect of nepotism on human resource managers."International Journal of Manpower, 15 (1), 60-67

Jones, M. (1992) "Failure to promote women: a serious loss." Caterer and Hotelkeeper, 9 January, p.12

Jordan, F. (1997) "An occupational hazard? Sex segregation in tourism employment." Tourism Management 18, (8) 525-534

Kattara, H. (2005) "Career challenges for female managers in Egyptian hotels." International Journal of Contemporary Hospitality Management 17, (3) 238-251

Krueger, R. A., \& Casey, M. A. (2014). Focus groups: A practical guide for applied research. Sage publications

Lee, C., \& Chon, K. S. (2000). "An investigation of multicultural training practices in the restaurant industry: the training cycle approach."International Journal of Contemporary Hospitality Management, 12 (2), 126-134

Li, L., \& Leung, R. W. (2001) "Female managers in Asian hotels: profile and career challenges." International Journal of Contemporary Hospitality Management 13, (4) 189-196

Linehan, M., \& Scullion, H. (2001) "Challenges for female international managers: evidence from Europe." Journal of Managerial Psychology 16, (3) 215-228

Linehan, M., \& Scullion, H. (2001) "Challenges for female international managers: evidence from Europe." Journal of Managerial Psychology 16, (3) 215-228 
Liu, J., \& Wilson, D. (2001) "The unchanging perception of women as managers." Women in Management Review 16, (4) $163-173$

Magablih, K. (2000) "Role of Female Employees in the Hotel Industry of Jordan." Al Edari83, 181- 210

Magablih, K. (2006) "Dimensions of Women Participation in the Jordanian Tourism Industry." Abhath Al Yarmouk 22, (1) $95-122$

Masadeh, M. (2010) Human Resources in international hotel chains in Jordan: "Out-of-country" training determinants. Unpublished $\mathrm{PhD}$ thesis. Coventry University

Masadeh, M. (2013) "Women in the Hotel Industry: What's Missing from this Picture?" International Journal of Academic Research in Business and Social Sciences 3, (1) 573- 580

Maxwell, G. A. (1997) "Hotel general management: views from above the glass ceiling." International Journal of Contemporary Hospitality Management 9, (5/6) 230-235

Peacock, M. (1995) "A job well done": hospitality managers and success." International Journal of Contemporary Hospitality Management 7, (2) 48-51

Pierce, A. (2011). Financing Profile: Small and Medium-Sized Enterprises in Tourism Industries [online] available from Industry Canada website <http://www.ic.gc.ca/eic/site/061.nsf/eng/h_02239.html.>[23 November 2016]

Pine, R. (1997)"Hong Kong's changing hotel industry and the current and potential utilization of women in management and leadership roles" working papers, Hong Kong

Charlesworth, S., \& Baird, M. (2007)."Getting gender on the agenda: the tale of two organisations."Women in Management Review, 22(5), 391-404

Shirley, S. (1995) "Getting the gender issue on the agenda." Professional Manager, January, 12-14

Smith, P.L., \& Smits, S.J. (1994) "The feminisation of leadership?" Training and Development, February, 43-6

Statistics Canada. (2011), National Tourism Indicators, Catalogue No. 13-009-X, 2011.online] available from<http://www.statcan.gc.ca/pub/13-009-x/13-009-x2011002-eng.htm>[07 November 2016]

Tikekar, S.R. (2007) Epigrams from Gandhiji.[online] available from <http://www.mkgandhi.org/epigrams/w.htm>[15 December 2016]

Timo, N., \& Davidson, M. (2005) "A survey of employee relations practices and demographics of MNC chain and domestic luxury hotels in Australia." Employee Relations 27, (2) 175-192

The JordanianMinistry of Higher Education and Scientific Research (2018), The Annual Statistical Report on Higher Education in Jordan for the year, 2017-2018

The Jordanian Ministry of Tourism and Antiquities (2011), "Tourism Statistical Newsletter 2008", Volume 7-4 ${ }^{\text {th }}$ issue, [online] available from<http://www.mota.gov.jo/en/Default.aspx?tabid=121>[10 December 2016]

The World Bank. (2012) "World Development Indicators." Washington, D.C [online] available from <http://data.worldbank.org/sites/default/files/wdi-2012-ebook.pdf> [29 November 2016]

Treven, S. (2003) "International training: the training of managers for assignment abroad." Education + Training 45, (8/9) 550-557

Wong, C. S., \& Chung, K. M. (2003) "Work values of Chinese food service managers." International Journal of Contemporary Hospitality Management 15, (2) 66-75

Woods, R.H., \&Viehland, D. (2000) "Women in hotel management." Cornell Hotel and Restaurant Administration Quarterly 41, (5) 51-54

World Travel \& Tourism Council. (2011). “Travel \& Tourism 2011.” London, UK. [online] available from <http://www.wttc.org/site_media/uploads/downloads/traveltourism2011.pdf>[08 October 2016]

World Tourism Organization UNWTO (2012). "Gender and Tourism." Nigeria. [online] available from <http://www2.unwto.org/en/category/related/unwto/programme/ethics-social-dimension-tourism/gender-andtourism>[08 October 2016]

Würth, A. (2004) Women's Rights in the Arab world: Overview of the status of women in family law with special reference to the influence of Islamic factors. [online] available from <http://www.gtz.de/de/dokumente/enfrauenrechte-arab-welt.pdf> [06 November 2016] 